Artigo original

Hegemonia - Revista Eletrônica de Relações Internacionais do Centro Universitário Unieuro

ISSN: $1809-1261$

UNIEURO, Brasília, número 16, 2015, pp. 88-105.

Recebido em: 19/2/2015

Avaliado em:10/3/2015

Aprovado em: $28 / 4 / 2015$

\title{
A BUSCA DA INCLUSÃO POLÍTICA ATRAVÉS DO SUFRÁGIO UNIVERSAL QUALITATIVO E QUANTITATIVO
}

Luiz Augusto Oliveira Leite $^{1}$

Resumo: O objetivo deste artigo é demonstrar que a ação de votar assegura ao povo pleitear ações governamentais no processo político, bem como atuar para exercer através de uma argumentação pública objetiva políticas públicas e sociais, que além de promover a inclusão social, como forma de desenvolvimento democrático, possa garantir que os direitos fundamentais positivados na Carta Magna sejam aplicados a camada marginalizada pelo sistema. Ressalte-se que a lutas sociais e manifestações políticas fortalecem e legitimam as reivindicações populares. A inserção dos excluídos na arena política promove a garantia do mínimo de bem estar social e gera recursos para dinâmica do cenário político. Neste contexto em que a disputa pelo poder mediante a representatividade do capitalismo solapou os direitos sociais de grande parte da população, o Estado deve agir de forma eficaz para diminuir os efeitos negativos gerados pela crescente disputa ao poder político. Portanto, a ação do eleitorado assegurado pela relação jurídica na obrigação do voto não pode ser vista apenas como um "nicho clientelista", mas como uma maneira de capitar e capacitar a população desprovida de recursos, conhecimentos e participação política, bem como disseminar a educação no sentido da escolha certa.

Palavras-chave: Sufrágio universal, políticas públicas, voto, inclusão política.

Abstract: The purpose of this article is to demonstrate that the action of voting ensures the people demand government action in the political process and act to carry through an objective public reasoning public and social policies, which in

$1 \quad$ Mestre em Ciência Política pelo Centro Universitário Unieuro, Advogado graduado pela Universidade Paulista e Especialista em Direito Público pela Faculdade Processus, e mail: luizaugusto@adv.oabdf.org.br 
Artigo original

Hegemonia - Revista Eletrônica de Relações Internacionais do Centro Universitário Unieuro

ISSN: $1809-1261$

UNIEURO, Brasília, número 16, 2015, pp. 88-105.

addition to promoting social inclusion as a way of democratic development, to ensure that fundamental rights positivized the Charter to be applied to marginalized by the system layer. It should be noted that the social struggles and political demonstrations strengthen and legitimate popular demands. The inclusion of the excluded in the political arena promotes the guarantee of minimum social welfare and generates resources for dynamic of the political scene. In this context in which the struggle for power by the representative of capitalism undermined the social rights of much of the population, the state should take effective action to reduce the negative effects generated by the growing dispute the political power. Therefore, the electorate's action ensured by the legal relationship in the vote obligation can not be seen only as a "patronage niche", but as a way to capitar and empower the population devoid of resources, expertise and political participation, as well as disseminating education towards the right choice.

Keywords: Universal suffrage, public policy, vote, political inclusion.

\section{INTRODUÇÃO}

O voto obrigatório no Brasil tem forte influência burguesa, tendo em vista a exclusão sociopolítica de grande parte da população que é manipulada pela classe dominante e garante uma votação muitas vezes direcionada aos detentores do conhecimento político.

O desenvolvimento da sociedade hodierna, a influência dominante da burguesia e os anseios sociais motivaram o aumento da competitividade e disputa pelo poder, e que com a globalização a necessidade de capacitação pessoal se tornou inevitável.

Neste contexto, a participação popular tende a ser mais qualitativa em vez de quantitativa, ou seja, a manutenção do voto obrigatório pode ser uma ferramenta de controle social na medida em que a população aprimora seus conhecimentos políticos e usa sua capacidade de argumentação como forma de discussão pública para melhor escolha de seus representantes.

A obrigação de votar tem argumentos jurídicos e políticos favoráveis e contrários que vão além da obrigatoriedade de escolha, uma vez que a manipulação do eleitorado é 


\section{Artigo original}

Hegemonia - Revista Eletrônica de Relações Internacionais do Centro Universitário Unieuro

ISSN: $1809-1261$

UNIEURO, Brasília, número 16, 2015, pp. 88-105.

um problema de difícil solução pela fragilidade da fiscalização em meio a uma sociedade complexa de enormes necessidades sociais de inclusão econômica e reflete diretamente na escolha de um candidato.

Os antigos explorados que lutaram por liberdade são em grande parte excluídos pela falta de proteção e negligência do Estado perante os direitos sociais. A população vulnerável foi massificada pelo exercício do autoritarismo e da violência crescente da disputa globalizada e atualmente são manipulados, tendo como nexo causal sua vulnerabilidade.

Por ser assim, há argumentos favoráveis e contrários a esse dever de votar, e que reflete diretamente na reforma política nacional. Se por um lado votar ajuda a ter um compromisso com a política, fortalece um controle social e dissemina a vontade de mudança, por outro o voto inconsciente pode ocasionar uma escolha sem critérios concretos, manipulada e desqualificada.

Para Sen (2013):

A necessidade de objetividade para comunicação e para a linguagem da argumentação pública é seguida pelas exigências mais específicas de objetividade na avaliação ética, incorporando exigências de imparcialidade. A objetividade em cada sentido tem um papel nesse método de argumentação pública, e os papeis estão inter-relacionados, mas não são exatamente iguais.

Observa-se que a imparcialidade faz parte de uma boa argumentação pública. 0 conhecimento é ferramenta na luta pelo pleito social e para atingir uma objetividade política é importante a junção dos anseios da população por um grupo representativo de forma imparcial, que os transformará em uma lide direcionada a auxiliar na escolha do representante ideal da causa. 


\section{Artigo original}

Hegemonia - Revista Eletrônica de Relações Internacionais do Centro Universitário Unieuro

ISSN: $1809-1261$

UNIEURO, Brasília, número 16, 2015, pp. 88-105.

Desta forma, a camada sem proventos que por décadas foi marginalizada e passou a ser vista como uma nova fonte de captação de "votos" tende a alterar seu status quo, e participar ativamente no processo político representativo para disseminar a alteração do corpo político pela melhor escolha. A inclusão qualitativa desta classe no sistema político se tornou uma necessidade urgente.

A manutenção do voto obrigatório é uma forma de majorar a participação política qualitativa após uma política educativa. Evitar a participação quantitativa é uma forma de exclusão sociopolítica, bem como diminuir a chance de obter o voto na argumentação pública. Por ser assim, o eleitorado ativo e consciente deixa de ser bestializado e sua manutenção no sistema político é uma forma de controle social.

1 Argumentação pública e voto obrigatório como relação jurídica frente a exclusão social devido a negligência do Estado brasileiro na garantia da cidadania.

Primeiramente, pontua-se que o voto obrigatório teve início com o Código Eleitoral em 1932 mantido em nossa Carta Magna, como forma de participação política e exercício da democracia para escolha do representante para resolução dos pleitos populares.

O voto obrigatório tem uma função pública de evitar a desvirtualização do sistema democrático e proporcionar alteração da situação de vulnerabilidade de grande parte populacional.

Para Sen (2013):

Na verdade, a ligação fundamental entre argumentação pública, por um lado, e as demandas de decisões sociais participativas, por outro, é fundamental não apenas para o desafio prático de tornar a democracia mais efetiva, mas também para o 
Artigo original

Hegemonia - Revista Eletrônica de Relações Internacionais do Centro Universitário Unieuro

ISSN: $1809-1261$

UNIEURO, Brasília, número 16, 2015, pp. 88-105.

problema conceitual de basear uma idéia devidamente articulada de justiça social e da equidade.

A ausência de obrigação não ocasiona um contrato social por ser uma faculdade de fazer, e poderá acarretar a nulidade de ação do eleitorado vulnerável e desinformado, bem como poderá gerar uma forma de "clientelismo" de massa com benefícios oferecidos aos participantes do processo.

Destarte, o novo cenário criado pela recente manifestação popular, uma conscientização de controle social está surgindo, mesmo que fortemente influenciado pelas idéias burguesas, de Estado Mínimo, de participação política restrita, de leis protecionistas e manutenção do poder.

Os eleitores devem intervir nesta realidade, uma vez que são a parte da relação entre o cidadão, o Estado e o sistema político, mudando a realidade de uma ação protecionista para uma política voltada a reinserção ou real inserção no campo político brasileiro.

Para Muller (2014) o direito é uma forma que o indivíduo tem razoavelmente de exigir da sociedade a garantia que são positivadas e conquistadas pelas lutas sociais, por ser assim o direito às prestações, obrigações internas e interpretações externas devem ser submetidas no contexto sociopolítico para verificação de análise do fato como socialmente possível, e calculatoriamente desejado, sendo assim o voto obrigatório tem amparo jurídico e ampla defesa.

Não podemos ignorar que a ordem jurídica do Estado constitucional burguês da modernidade reduziu a um mínimo, a expressão normativa imediata para tratar da desigualdade social e das diferenças estatamentais ou de classe.

Portanto a votação qualitativa poderá proporcionar transformações significativas que beneficiarão os excluídos do sistema político por problemas relacionados à vulnerabilidade, desinformação e manipulação. 
Artigo original

Hegemonia - Revista Eletrônica de Relações Internacionais do Centro Universitário Unieuro

ISSN: $1809-1261$

UNIEURO, Brasília, número 16, 2015, pp. 88-105.

Neste sentido, estas ações de políticas públicas, o sufrágio universal e o controle social são formas de minimizar a injustiça social, tão presente quanto à justiça ora proclamada pelas lutas políticas.

Ressalte-se que a educação política é uma forma de proporcionar a permanência destes indivíduos neste sistema e assim fazer jus aos direitos fundamentais de segunda geração.

Para Hofling (2001):

Mais do que oferecer "serviços" sociais - entre eles a educação - as ações públicas, articuladas com as demandas da sociedade, devem se voltar para a construção de direitos sociais.

A participação política além de assegurar o controle social, possibilita que o Estado de Bem Estar Social não seja apenas uma característica conceitual. A relação contratual do eleitorado e seu representante vai além da ação de escolha, mas de uma obrigação da relação política criada e protegida juridicamente da obrigação de fazer.

A participação popular da arena política está presente na definição dos direitos coletivos e difusos dos Estados Contemporâneos. Destaca-se que apenas parte da população usufrui deste conceito, uma vez que o descuido do Estado é uma realidade que atinge a parcela que não consegue desenvolver seus conhecimentos, ficando privada de liberdade, do desenvolvimento individual e da inclusão sociopolítica.

Vale frisar que as camadas sociais mais baixas da população apesar de organizáveis, não são organizadas. Elas são pouco representadas nas associações existentes, em 


\section{Artigo original}

Hegemonia - Revista Eletrônica de Relações Internacionais do Centro Universitário Unieuro

ISSN: $1809-1261$

UNIEURO, Brasília, número 16, 2015, pp. 88-105.

suas posições de liderança e no direito administrativo torna-se mais notório, pois a burocracia rege a sua aplicação organizada.

No âmbito dos Direitos Fundamentais em que dados políticos estão inseridos, reivindicar jurídico-políticamente a ordem liberal e democrática, deve ter a preocupação de igualdade nos componentes de clamor social conforme o Estado de Direito, para que garantias desse Estado de Direito também não retrocedam ou sejam retiradas ao mesmo tempo, e podem ser demandadas do voto obrigatório de uma relação contratual juridicamente amparada

Sendo assim, o Brasil é um país que não alcançou plenamente um modelo de Estado de Bem Estar Social, tendo em vista a dificuldade de promover em conjunto os três pilares da cidadania, ou seja, a promoção dos direitos sociais, políticos e civis. Desta forma, a sociedade demorou a exigir soluções democráticas e impor maior representação política das classes excluídas.

Para Carvalho (2006):

Para promoção da cidadania no Brasil os direitos sociais precedem os políticos e civis, diferente da Inglaterra que os direitos políticos precedem os civis e sociais.

Neste contexto, a não obrigação de votar pode provocar uma grande exclusão da população na arena política, por estar sem acesso às ferramentas de capacitação, uma vez que os benefícios do progresso não foram distribuídos de forma igualitária ao povo brasileiro que ficou à margem do sistema por décadas.

Por ser assim, a responsabilidade do Estado é garantir a cidadania, bem como resolver os problemas emergentes, que são oriundos de carências da população massificada por séculos de ausência de governabilidade. A presença da sociedade na 
Artigo original

Hegemonia - Revista Eletrônica de Relações Internacionais do Centro Universitário Unieuro

ISSN: $1809-1261$

UNIEURO, Brasília, número 16, 2015, pp. 88-105.

arena política pode ser garantida no mesmo sentido da obrigação de educação universal, evitando uma maior ausência do eleitorado com conseqüências benéficas apenas para parte do povo.

2 Participação pública brasileira e ações de inclusão social asseguradas pelo sufrágio universal

A campanha eleitoral brasileira, além da disputa dos candidatos, pode promover inclusão política de maneira qualitativa, voltada educação e argumentação objetiva simultaneamente, uma vez que a inserção ou a reinserção da massa de eleitores poderá assegurar o controle social, bem como aumentar a conscientização popular frente às necessidades urgentes e emergentes.

Nota-se que a argumentação objetiva é feita com a inclusão sociopolítica das pessoas, inclusive das menos favorecidas em busca do Estado de Bem Estar Social. O sufrágio universal além de ser uma conquista que beneficia a população, oferece ao eleitorado um grande potencial para impulsionar a responsabilidade dos candidatos das regiões nas quais esse segmento se concentra, trazendo esse público à política formal, possibilitando ao Estado intervir fortemente nas suas funções basilares.

O que realmente importa, contudo, não é contrapor "votos versus benefícios", e sim por em prática um sistema político eficaz, com eleitorado consciente e votação qualitativa em conjunto com a quantitativa, uma vez que não é possível separar a qualidade exercida pelo maior número de pessoas para atingir um sistema político democrático.

Neste sentido, assegurar qualidade e quantidade na eleição brasileira poderá auxiliar na formulação de projetos para campanhas eleitorais que completam segurança econômica, transparência, equidade, imparcialidade e objetividade. Deixar os pobres 


\section{Artigo original}

Hegemonia - Revista Eletrônica de Relações Internacionais do Centro Universitário Unieuro

ISSN: $1809-1261$

UNIEURO, Brasília, número 16, 2015, pp. 88-105.

à própria sorte não é socialmente justo, nem constitui uma política democrática e sim exclusiva.

Como comparação, cita-se as injustiças sociais que ocorre atualmente na Índia, em que grande parte ocorre devido à falta controle social pela fragilidade da argumentação pública devido à exclusão de grande parcela de indianos da arena política.

Para Sen (2015):

O que é fundamental avaliar, no entanto, é se os protestos mais ruidosos e politicamente poderosos refletem de maneira adequada as privações e as injustiças que os indianos sofrem de modo contínuo. A importância e o poder político dos indianos relativamente privilegiados - mesmo aqueles que não são de fato ricos, mas cuja renda e cujos padrões de vida os situam bem acima da média da Índia- tendem a servirs como barreira para a atenção que as vozes dos pobres podem com efeito obter o resultado, com suficiente frequência, é uma exclusão, em muitas questões políticas, da maioria das pessoas que sofrem provações imensas na Índia.

Evidencia-se que a argumentação objetiva, além do controle social assegura que a massa da população vulnerável aos poucos se transforma em objetivos políticos, e a manipulação começa a enfraquecer dando lugar à justiça social pelas lutas justas.

Além de contribuir com a própria conscientização, o voto é a confirmação da importância do sufrágio universal e cria um ciclo virtuoso que leva benefícios a todo o entorno do eleitorado.

Desta forma, os incentivos para uma votação consciente estão diretamente ligados à obrigação de fazer, assim como a educação tem maior eficácia quando se torna um direito positivado com uma responsabilidade normatizada. 


\section{Artigo original}

Hegemonia - Revista Eletrônica de Relações Internacionais do Centro Universitário Unieuro

ISSN: $1809-1261$

UNIEURO, Brasília, número 16, 2015, pp. 88-105.

Observa-se que a cultura gerada pela educação suscita uma transformação na sociedade, que passa a lutar pelos seus direitos em decorrências dos seus deveres cumpridos.

No mesmo raciocínio, a conscientização política é uma luta constante diretamente ligada à participação popular e ao controle social advindo da capacidade de argumentar, bem como de agregar sua influência no sistema político nacional, o que antes não acontecia, devido à inacessibilidade em conhecimentos jurídicos e forças políticas que enfraquecem com a manipulação a ações protecionistas, desviando o foco das principais funções do governo.

Desde modo, a necessidade do Estado de intervir em outras áreas seculares e vultosos investimentos em políticas assistencialistas, fez com que a população ficasse à mercê de "ações emergenciais" para garantir o mínimo de dignidade. 0 desvio das funções pode provocar o que Chomsky denomina de Estados fracassados, onde a população sofre com problemas sociais de violência e os governantes agem ilegalmente para suprir as questões negligenciadas.

Para Noam Chomsky (2009):

Os Estados fracassados não têm capacidade de dar segurança aos seus cidadãos e se posicionam fora do alcance das leis.

Neste pensamento, fornecer possibilidades para que o indivíduo tenha capacidade de desenvolver sua liberdade e se tornar ativo na política, é uma ação de proteção à dignidade humana, tendo em vista a obrigação de proteção do Estado ao cidadão. Saúde, educação e segurança são deveres do Estado e sua principal função é proporcionar ferramentas para que seu povo possa desenvolver habilidades que irão proporcionar a liberdade de usufruir igualmente das benfeitorias sociais e coletivas. 


\section{Artigo original}

Hegemonia - Revista Eletrônica de Relações Internacionais do Centro Universitário Unieuro

ISSN: $1809-1261$

UNIEURO, Brasília, número 16, 2015, pp. 88-105.

Neste raciocínio, os agentes públicos brasileiros podem originar ações de cooperativismo de informação política para que as pessoas de baixa renda possam ser beneficiadas pelo voto consciente e saiam da situação de extrema pobreza, viabilizando a expansão da participação popular, com possibilidade de liberdade contratual, política e pessoal.

Desse modo, na medida em que um sistema social está baseado em desigualdade ou a permanência desigual, formas de expressão da desigualdade influem genericamente na realização do direito, por causa da possibilidade de normatização jurídica de conteúdos políticos oriundos de lutas populares e representativas da sociedade complexa hodierna. Contudo isso, é importante estabelecer a relação político-jurídica do voto para garantir a continuidade do sufrágio universal.

Os direitos sociais conquistados no decorrer da história é o sucesso de lutas populares, de reivindicações da grande massa eleitoral que representa o setor brasileiro de maior quantidade da América Latina, em que a forte atuação do governo brasileiro nas questões sociais e na promoção de políticas públicas é uma resposta as vozes do eleitorado.

O voto é a manifestação política individual de uma proporção significativa, pois motiva uma força coletiva de maior impacto no setor político e consequentemente na economia, oferecendo maior estabilidade ao cidadão, maior segurança da coletividade e possibilidade de direcionar novos investimentos nas funções primárias governamentais.

Ressalta-se que no Brasil o voto qualitativo continua menos desenvolvido, o que prejudica a eficácia das políticas de inclusão social na arena política, uma vez que o indivíduo necessita de impulso para iniciar suas atividades ou ações e se manter ativo no sistema político.

Para Sen (2015): 


\section{Artigo original}

Hegemonia - Revista Eletrônica de Relações Internacionais do Centro Universitário Unieuro

ISSN: $1809-1261$

UNIEURO, Brasília, número 16, 2015, pp. 88-105.

As queixas dos "relativamente privilegiados, mas não os mais privilegiados", que constituem a categoria das assim chamadas " pessoas comuns" recebem uma atenção tremenda, e as perspectivas desse grupo facilmente mobilizável são predominantes nos principais partidos políticos. Isso está em nítido contraste com a relativa falta de atenção para as enormes e duradouras - privações dos mais desfavorecidos da sociedade indiana.

Nota-se que a permanência da desigualdade indiana esta diretamente ligada à atenção nos partidos políticos que dependem diretamente da participação ativa dos seus componentes e da força representativa no contexto social.

Desta forma, a massa mobilizável tende a conseguir aprovação de políticas públicas para beneficiar sua vida através de sua ação política e acúmulo de votos mobilizados. O Estado pode motivar a criação de uma política consciente e justa para relação da capacidade humana de solucionar problemas, gerar benefícios e laborar em prol de mais conforto para a sua existência de forma constante, duradoura e não apenas uma falsa ideia de liberdade momentânea de ações protecionistas.

As ações de educação política no contexto da população brasileira, além de promover o aumento da força competitiva nos projetos políticos é uma forma de proporcionar a permanência em campanhas eleitorais instrutivas e não impositivas. Neste sentido, a implantação e execução das políticas públicas de inclusão política, o até então desprovido de recursos e potencialidades, passa a desenvolver qualidades como garantia de liberdade no contexto sócio político atual.

Para Amartya Sen (2000):

Há muitos males sociais que privam as pessoas de viverem minimamente bem: a pobreza extrema, a fome coletiva, a subnutrição, a destituição e marginalização 
Artigo original

Hegemonia - Revista Eletrônica de Relações Internacionais do Centro Universitário Unieuro

ISSN: $1809-1261$

UNIEURO, Brasília, número 16, 2015, pp. 88-105.

sociais, a privação de direitos básicos, a carência de oportunidades, a opressão e a insegurança econômica, política e social.

O voto além de manifestar as vozes sociais possibilita a permanência no sistema político de eleitores, no lugar de "clientes" e muda o cenário como forma do exercício da justiça social, uma vez que a geração sustentável do voto consciente ameniza os malefícios causados ao cidadão de baixa renda do atual sistema capitalista.

Para Prahalad (2009):

se pararmos de pensar nos pobres como vítimas ou como um fardo e começar a reconhecê-los como empreendedores incansáveis e criativos e consumidores conscientes de valor, um mundo totalmente novo de oportunidades se abrirá.

Observa-se que os pobres são capazes de exercer ações políticas, ser criativos e criador de oportunidades.

Então, se as políticas públicas são remédios para os malefícios do desenvolvimento, do progresso e da mundialização do capitalismo; a eficácia das políticas de conscientização nos bolsões pode provocar um ganho de oportunidades para impedir que cidadão cada vez mais massificado pela brutal disputa de poder continue somente a possibilitar uma grande concentração de votos, e passe a ser o principal fato gerador para minimizar as desigualdades sociais.

A possibilidade de provocar maior conscientização diminui os problemas gerados pela falta de argumentação objetiva. As políticas públicas podem ser motivadas por necessidades de inclusão e não por dependência de ações assistencialistas ou 


\section{Artigo original}

Hegemonia - Revista Eletrônica de Relações Internacionais do Centro Universitário Unieuro

ISSN: $1809-1261$

UNIEURO, Brasília, número 16, 2015, pp. 88-105.

protecionistas que não impulsionam a ações políticas, nem possibilitam o exercício da cidadania e do sufrágio universal.

Para Vicente Faleiros (2009):

políticas públicas como 0 conjunto de diretrizes governamentais voltadas, legalmente, ao propósito de se criar condições de desenvolvimento sócio-econômico em favor de uma dada população de um determinado país. Obviamente esse conceito diz respeito à interferência estatal na vida social para a perseguição de objetivos pautados sob a égide do bem comum. As definições de políticas públicas sempre dizem respeito à alocação de recursos financeiros, resultado de múltiplos interesses aos quais o Estado deve atender racionalmente e, em consonância com a vontade da sociedade, executar programas que levem em consideração oportunidades e necessidades coletivas. As políticas públicas, como ações estatais, assumem múltiplos aspectos. Do ponto de vista econômico, estão relacionadas à dimensão da racionalidade quanto à escolha de prioridades, visto que os recursos.

Nota-se que as ações estatais assumem múltiplos aspectos e são o resultado de necessidades emergenciais observadas em grande parte do clamor social que possibilita o direcionamento de prioridades.

Sendo assim, o sufrágio universal é assegurado pelo voto quantitativo e suas consequências pelo voto qualitativo. As políticas públicas de conscientização podem ser voltadas ao aumento da qualidade e não da possível diminuição do número de eleitores.

Os direitos sociais das pessoas que formam os bolsões foram prejudicados concomitantemente ao desenvolvimento da sociedade hodierna. Dessa forma, o 


\section{Artigo original}

Hegemonia - Revista Eletrônica de Relações Internacionais do Centro Universitário Unieuro

ISSN: $1809-1261$

UNIEURO, Brasília, número 16, 2015, pp. 88-105.

sufrágio universal é uma garantia de manutenção de todos na arena política para uma esperança de mudança social.

Para Vera Telles (1999):

(...)os efeitos devastadores das mudanças em curso no mundo contemporâneo, demolindo direitos que mal ou bem garantem prerrogativas que compensam a assimetria de posições nas relações de trabalho e poder, e fornecem proteções contra as incertezas da economia e os azares da vida.

A injustiça social se tornou presente nos diversos momentos históricos do capitalismo. A exploração do eleitorado contradiz o preceito de liberdade e a exclusão social contradiz a teoria do Estado de Bem Estar Social.

Nesse cenário, políticas públicas de redução de pobreza, em escala, passam a ser demandadas com urgência, trazendo luz aos programas de inclusão popular e não de exclusão ou ausência de ação por falta de conhecimento.

Desta maneira, é dever do Estado brasileiro impor ações que garantam a condição de cidadão em todas as suas esferas, uma vez que os direitos individuais e coletivos da massa foram lesados em prol da ganância e disputa de poder.

A participação do maior número de pessoas na eleição é uma forma do Estado de garantir condições de manifestação aos indivíduos atingidos com a pressão externa do sistema difuso do capitalismo mundializado, bem como promover a cidadania e impulsionar a democracia no país.

Futuramente as experiências de qualidade e quantidade em conjunto vão relatar com evidências comprobatórias as melhorias para geração futura, redução de pobreza e melhoria nos indicadores econômicos regionais e nacionais. 


\section{Artigo original}

Hegemonia - Revista Eletrônica de Relações Internacionais do Centro Universitário Unieuro

ISSN: $1809-1261$

UNIEURO, Brasília, número 16, 2015, pp. 88-105.

\section{Considerações finais}

A ação de votar está diretamente ligada ao direito adquirido do sufrágio universal. As conquistas sociais resultantes de uma argumentação objetiva que possibilita um controle social efetivo é a expressão do conceito de soberania, bem como do Estado de Bem Estar e de Liberdade.

O conceito de justiça social, a necessidade de adquirir conhecimentos e as alianças políticas são virtudes do Estado Moderno. Os ideais revolucionários de liberdade, igualdade e fraternidade são influentes até a idade contemporânea.

O grande defeito do Estado Moderno é a exclusão da grande parte da população das virtudes e ideais da classe dominante, bem como a incapacitação ao exercício político que se torna cada vez mais presente no contexto da disputa eleitoral.

A injustiça social, as formas indignas de sobrevivência, exploração de trabalhadores, dificuldade de acesso a educação, impossibilidade de acumular riquezas e competir isonomicamente no mercado em expansão, submissão as regras impostas e a privação de liberdades individuais assolam o povo que lutou por liberdade, buscou proteção e conquistou o direito de propriedade e ao voto. Este povo se tornou refém da minoria que detém o poder de manipular o Estado e impor suas regras, bem como transformar o eleitorado em clientes do sistema.

Neste contexto de extrema competição e exclusão social, a ação de votar é uma importante ferramenta de apoio ao Estado na implementação de políticas públicas que auxiliam os indivíduos na busca de reinserção social, escolha do melhor representante e do voto consciente.

Impulsionar a política com a conscientização do eleitorado ora bestializado, exclui a classe de "clientes" em detrimento do eleitor. A quantidade em conjunto com a qualidade é promover a cidadania e proporcionar aos eleitores a possibilidade de aumentar de forma permanente sua argumentação sustentável na arena política. 


\section{Artigo original}

Hegemonia - Revista Eletrônica de Relações Internacionais do Centro Universitário Unieuro

ISSN: $1809-1261$

UNIEURO, Brasília, número 16, 2015, pp. 88-105.

Buscar a liberdade do povo pelo desenvolvimento de uma condição crítica do bem estar social, por uma capacidade de expressar e reivindicar os direitos minados historicamente, como forma de resolver o âmago da indignidade gerada pela submissão imposta, é proporcionar possibilidades de qualificação pessoal em prol de uma política protecionista que priva o indivíduo de expandir seus limites no sistema capitalista globalizado.

As ações protecionistas que causam a comodidade dos beneficiários devido uma sensação de exclusão e incapacidade não solucionada devem ser substituídas por políticas de incentivos à participação popular.

Orientar os representantes públicos para que estes possam refletir na condução do eleitorado a uma alteração do "status quo" de estagnação, para uma liberdade pautada na produtividade, na ação de transformação, além da inclusão social, fortalece uma política sustentável, legítima e cidadã.

A necessidade de gerar uma visão e missão política de maior intervenção do eleitor na formulação de projetos ligados a saúde, educação e segurança é uma forma de minimizar o desrespeito aos direitos fundamentais.

O governo pode zelar pelos princípios constitucionais, bem como, proporcionar melhor qualidade de vida ao cidadão, obtida com o desenvolvimento de habilidades individuais e participação política, para atingir a liberdade social, assegurado pela obrigação de votar de forma consciente.

Metódico-juridicamente, contudo, há de ser levada em conta a previsão pessimista, alimentada pela suposta ingovernabilidade dos Estados Constitucionais, como variante ao menos possível, tendo por conseqüência a redução dos elementos democráticos e o incremento dos elementos autoritários do sistema político, inclusive da família constitucional ocidental.

É marcante enquanto razões do afastamento do "estado fático" em face do "estado de dever-ser" próprio do Estado de Direito, que é a carência de realização fática do 
Artigo original

Hegemonia - Revista Eletrônica de Relações Internacionais do Centro Universitário Unieuro

ISSN: $1809-1261$

UNIEURO, Brasília, número 16, 2015, pp. 88-105.

direito vigente ou é um interesse de não colocar em evidência as verdadeiras razões que tornam as decisões hodiernas transparentes ou não.

\section{REFERÊNCIAS BIBLIOGRÁFICAS}

ARENDT, Hannah. A condição humana. $10^{a}$ ed. - Rio de Janeiro: Forense Universitária,2003.

CARVALHO, José Murilo. Cidadania no Brasil - o longo caminho. Rio de Janeiro:

Civilização Brasileira, 2006.

CHESNAIS, F. A mundialização doCapital. São Paulo: Xamã, 1996.

CHOMSKY, Noam. Estados Fracassados. Rio de Janeiro: Bertrand Brasil, 2009

DALLARI, Dalmo. Elementos de Teoria Geral do Estado. 32 edição - 2013

FRITSCH, Winston. Apresentação. In: SMITH, Adam. Investigação sobre a natureza e causas da riqueza das nações. Tradução de João Baraúna. São Paulo: Abril Cultural. V.1,1983

HAYEK, Friedrich A. O Caminho da Servidão. Trad. De Leonel Vallandro. 2a ed. São Paulo: Globo, 1977.

HOFLING, Heloisa. Estado e Políticas (públicas) sociais. Cadernos CEDES, Campinas no 55, p. 30-4,novembro de 2001

LENZA, Pedro. Direito Constitucional Esquematizado. São Paulo: Malheiros 2006, pp. 517.

MULLER, Friedrich. Metódica Jurídica e Sistema Político. Joinvile, 2014.

SALVADOR, Evilasio. Fundo público e seguridade social no Brasil. São Paulo: Cortez, 2010.

SEN, A. K. Desenvolvimento como liberdade. São Paulo: Companhia das Letras, 2000

SEN, A. K. Glória incerta. A Índia e suas contradições. São Paulo: Companhia das Letras, 2015 